\title{
Social Applications: Revenue Models, Delivery Channels, and Critical Success Factors - An Exploratory Study and Evidence from the Spanish-Speaking Market
}

\section{Marcelo Nogueira Cortimiglia ${ }^{1}$, Antonio Ghezzi $^{2}$ and Filippo Renga ${ }^{3}$}

${ }^{1}$ Federal University of Rio Grande do Sul, Industrial Engineering Department, cortimiglia@producao.ufrgs.br Politecnico di Milano, Department of Management, Economics, and Industrial Engineering,

2 antonio.ghezzi1@polimi.it, ${ }^{3}$ filippo.renga@polimi.it

Received 29 January 2011; received in revised form 15 April 2011; accepted 18 May 2011

Abstract

In the context of growing interest in both Mobile-Internet convergence and Web 2.0 social technologies, this article investigates the business opportunities derived from offering Social Applications in the convergent scenario, particularly regarding Social Network and Content Sharing services. Given the business model structural deficiencies identified in literature for this type of convergent services, the investigation is oriented towards the role of the technology delivery channels (either Internet and/or Mobile) and revenue appropriation strategies. A mixed-methods research strategy was employed consisting of a cross-sectional survey of 124 Social Application services offered in Spanish language and seven case studies with representative Social Network and Content Sharing services. While the aim of the survey was to map and identify the overall main characteristics and business model dimensions of Social Applications, the case studies' objective was to understand the strategic reasoning behind business model design and evolution. The research offered a detailed view on the dynamics of Social Network and Content Sharing services, showing how the revenue strategies are tightly linked to the technological delivery channel. Finally, six critical success factors for business models of Content Sharing and Social Network services were identified.

Keywords: Social technologies, Business models, Content sharing, Social networks, Critical success factors 


\section{Introduction}

The diffusion of mobile technologies all over the world in recent years is undisputed. In fact, the so-called Wireless Revolution can already be considered a cornerstone of the ICT industry, with profound impacts at both firm- [5], [27], [48], [65], [69], [81], [96], [103] and industry levels [4], [28], [43], [49], [53], [54], [74]. A particular topic that has been gaining importance over the last few years is that of the perceived shift of Mobile Telecommunications' focus from voice transmission to data transmission (and related value-added applications and services) [9], [11], [23]. Among mobile value-added services, Internet access is perhaps the most relevant business opportunity nowadays as it lays at the center of the Mobile-Internet convergence trend in act. [59] estimates that more people will connect to the Internet through a mobile device than desktop PCs in 2014. Moreover, according to recent estimations the number of mobile broadband subscriptions will surpass 1 billion by 2011 [42]. It seems that Mobile Web has reached, or is in the fringe of reaching, a critical mass of users to support large scale business models.

At the same time, another important trend in contemporary ICT business environment is the consolidation of the Web 2.0 phenomenon, as illustrated by Time's magazine choice for their annual Person of the Year award back in 2006: "You" [33]. Based on Alexa popularity rankings, [94] show the unquestionable rise of Web 2.0: while in 2004 no Web 2.0 propriety was listed among the top 20 English language sites, in 2006 this number was already six, growing to eight by 2008 (including five among the top 10). Moreover, a number of important economical transactions involving prominent Web 2.0 websites in the last few years evidence the consolidation of the phenomenon [6], [26], [31], [57], [98].

One particular type of Web 2.0 service at the forefront of business and academic interest is that of Social Applications, that is, digital services that allow or facilitate social interaction and communication among users, either directly or mediated by some kind of content, such as social network sites, content sharing services, content communities, instant communication tools, social bookmarking mechanisms, wikis, and blogs [20], [21], [61], [70]. Among Social Applications, both Social Network and Content Sharing services are showing particularly impressive growth rates. [50] found out that the percentage of U.S. adult Internet users that have at least one profile in an online SNS has more than quadrupled from 2005 to 2009, increasing from $8 \%$ to $35 \%$. This share goes up to $75 \%$ of the young adults ages 18 to 24 , and to $57 \%$ of adults between ages 25 and 34 . Perhaps the most well-known example of Social Networks sites is Facebook, a service that displayed triple-digit growth in both usage and registered users and attracted sizeable financial investments in the last few years. Similarly, market analysis companies show that Internet users constantly increase the amount of time they spend consuming media online. In the USA, by 2008 almost $75 \%$ of internet users watched videos online [62]. The leading Social Application Content Sharing service is YouTube, acquired by Google in 2006 in a transaction worth more than 1.65 billion dollars [31] and responsible for nearly $40 \%$ of the online video market in the US [18].

In this context, it is only natural to consider the business opportunities that arise from transposing Social Applications to the convergent Mobile-Internet scenario. For instance, both market-leading services mentioned above (Facebook and YouTube) already have consolidated the mobile version of their web proprieties and are reporting positive results. However, there are still a number of unresolved issues regarding the business models of convergent social technologies, especially for services that do not enjoy the market leadership benefits that the aforementioned behemoths possess.

Firstly, it is not clear how the value delivery and proposition dimensions of business models should be structured given the inherent mobile device's restrictions in terms of computing power, screen size and input and the characteristics of social content consumption in mobility. For instance, the small screens and keyboards of mobile devices can hinder the consumption of mobile video and difficult text input, while GPS-enabled phones can incorporate location-based information into Social Applications. All these value proposition delivery channel specificities must be considered when designing the functionalities offered and the user needs that can be fulfilled by the service. Similarly, mobility characteristics of personalization, localization, ubiquitousness push-capability [15], the existence of an already established and trusted payment channel in the form of the operator's bill [22], and the mobile consumer propensity to pay for premium content and services should be taken into account when considering the business model value delivery dimension for Social Network and Content Sharing services.

Secondly, while consumer adoption and diffusion of convergent Social Applications is becoming a reality, there are many doubts about the design of successful value appropriation strategies [17], [30], [82], [86], as evidenced by the reported difficulties in transforming popularity and usage indicators into profitable and sustainable revenue flows. Market analysts even hint at the possibility of a 2.0 version of the dot.com collapse at the dawn of the $21^{\text {st }}$ century [17], [72], [86], [100]. In particular, while trying to explore advertisement-related revenue, results have been largely unsatisfactory because of a combination of lack of user interest, advertiser reluctance, and misguided advertisement strategy based on traditional models that are not adequate to social media [8], [17], [86]. To make things worse, it has been argued that subscription-based revenue models are not adequate to the open, participatory ethos of Web 2.0 [45]. 
Furthermore, it must be stressed the almost inexistence of academic literature in the field of business management dealing with business models of convergent Social Applications. Published research tangent to this area is mostly technical, dealing with innovative proposals of technology application or usability and user adoption issues. The literature gap regarding business models of Social Applications is underlined by a recent report about the future and challenges of European research regarding user-centric media [37] and by scholars from sociology and communication sciences [7]. The few works in the field of technology management include mostly exploratory studies about specific issues such as the role of virtual communities as intermediaries in e-Business [44], the success of firms' ventures in Social Applications from a business-to-business perspective [86], revenue models for social network sites [25], and advertising on Web 2.0 applications [8].

Thus, the objective of this paper is to investigate the overall relationship between Web 2.0 Social Applications and mobile technologies and the possible implication that this synergy might have in their business models. In particular, special emphasis will be given to the Spanish-speaking market and to Social Networks and Content Sharing categories of Social Applications. Two main research issues guide the investigation: the role of the technology delivery channels (either Internet and/or Mobile) in a multi-channel value delivery strategy and the value appropriation strategies adopted by these services. A number of critical success factors to business models of Content Sharing and Social Network services are then highlighted, and their identification is based on the comparative analysis of case study results and secondary sources.

The paper opens with a brief presentation of the Mobile-Internet convergence and Social Application themes; the research problem and research objective are hence stated. Section two presents a Literature Review on the topics of Web 2.0 and Mobile-Internet convergence, Social Applications and Business Models. Next, the Research Framework is provided in section three, and research results are discussed in section four. Finally, in section five, conclusions are drawn, limitations to the present work are discussed and suggestions for further investigation are offered.

\section{Literature Review}

The conceptual framework upon which this research is based on is constituted by three topics: the Mobile-Internet convergence, dealing with the characteristics of the technological delivery channels and their associated value drivers, the Social Application concept, which properly defines the object of study, and the business model construct, which guides the investigation on the actual business ramifications of Social Applications. In this section, a brief review of these three topics is presented.

\subsection{Web 2.0 and the Mobile-Internet Convergence}

Although the perception that Internet technologies caused innumerable impacts in the contemporary society is not new, one of its most intriguing aspects in the last few years has been the evolution and posterior consolidation of the Web 2.0 phenomenon. There is still no consensus about a unique definition for the Web 2.0 concept, but business analysts and academics alike agree that it represents a paradigmatic change in the way Internet technologies are used: from a linear structure of one-to-many content production, distribution and consumption to a participatory structure based on open, inclusive, collaborative and customizable applications that allow users to collectively create, share, and use digital content [52], [61], [63], [64], [70].

The set of principles by [63] is widely perceived as a first authoritative attempt to define Web 2.0. It proclaims that the web should be viewed as a platform to develop services, which by their turn should be designed to be openly mixed and assembled, in a culture of constant experimentation. Moreover, services should focus on delivering a rich user experience, be designed in a way that their performance - and consequent value - improve automatically the more it is used, and capitalize on data access and network effects. Understandably, this requires intense and active user participation [100].

A natural consequence of [63] reasoning, thus, is the emphasis on services and applications as elementary constructs of Web 2.0 [24], [34], [71], [80], [101]. For the purposes of this paper, a comprehensive but non exhaustive list of Web 2.0 technologies drawn from [19], [52], [61], [63], [70] and [97] includes: blogs, wikis, RSS, social bookmarking, content tagging, social networks, content sharing, syndication and/or aggregation, and thematic communities.

Another approach to defining Web 2.0 considers its social aspect [19], [70], [83]. The fundamental construct of the Web 2.0 then becomes the users themselves and, more importantly, the relationships and interactions among them. Users directly interact with other users in a much larger scale than before, to the point of constructing and maintaining social relationships and, in the process, coming up with new and innovative content [87]. Interaction, indeed, can be identified as the defining Web 2.0 element. Consequently, value creation in Social Applications derive from the potential results of user interactions, that is, Social Applications can generate value for users in the form of social capital [30], [77] by fulfilling their informational, communication, social, entertainment, business, and selfexpression needs- a concept long established in e-Business [10], [38], [46], [51], [68]. 
While the Web 2.0 phenomenon attracted significant interest from the business and academic communities in the last few years, the same cannot be said about its extension to the mobile dimension, the so-called Mobile 2.0. Among the few attempts to analyze this concept, some authors state that it represents the next generation of mobile data services [40], while others see it as the extension of Web 2.0 services and applications to the mobile domain [32]. Thus, technical and social approaches to define Web 2.0 are in a certain way replicated in this convergent Mobile-Internet 2.0 phenomenon.

For instance, [41] list a series of technical trends that can be considered as defining traits of Mobile 2.0 concept. These include full browsing capabilities, AJAX-enabled dynamic content, mixed and assembled open applications, navigation enhanced with RFID and barcode, and emergence of mobile UGC (user-generated content) and social networks, all of which can be understood as mobile equivalents of the technological features that enabled the socialization of the Web environment. However, as [36] and [55] point out, Mobile-Internet 2.0 applications cannot be a simple transposition of their Web 2.0 equivalents; they must exploit the unique characteristics of mobile devices and mobility in order to enhance and enrich the interactions allowed.

[15] mentions four mobile value proposition attributes: ubiquity, convenience, localization and personalization. By ubiquity, he indicates the fact that most mobile devices are constantly connected to the network, resulting in availability at virtually any time and everywhere. Similarly, convenience means that mobile users are not restricted by usual time and place constraints, while the localization attribute indicates the ability to easily locate and identify the mobile user. Finally, by personalization [15] means the fact that mobile devices are extremely personal, usually directly linked to only one user, with his own preferences and desires for self-expression.

It is clear that these mobile value proposition attributes are aligned with many of the Web 2.0 principles. Localization and personalization, for instance, can potentially enhance the user empowerment effect, as well as open up new venues for social interaction enriched by awareness and location information. Furthermore, the ample diffusion of mobile devices with multimedia capability can intensify the user tendency to create, diffuse and share [75], thus reinforcing the inherent interactivity characteristics of the mobile devices.

Thus, it seems that whatever way one chooses to interpret the convergent Mobile-Internet 2.0 scenario, it invariably involves - and enriches -the concept of interaction between users that is characteristic of the Web 2.0 phenomenon. On the other hand, the issue for enterprises offering Social Applications in such a scenario of merging technologies is to identify the roles of both channels in creating value for users and appropriating value for the companies.

\subsection{Social Applications}

In the context of increased importance of the Web 2.0 social aspect and emergent convergence between mobile and Internet technologies, the concept of Social Applications is introduced as mobile- or web-based applications that allow or facilitate social interactions between users [19]-[21], [35], [44], [58], [70], [83]. In line with the sociotechnical perspective on Web 2.0, the success of Social Applications is based both on usability and sociability dimensions, and the fit between them [47]. Social Applications includes content sharing, social networking, communication, discussion and community building, social gaming, blogging, wikis, collaborative work, dating, business networking and virtual world websites and mobile services.

An important element of the conceptual framework that supports this research is a classification model for MobileInternet 2.0 Applications that uses interaction as its main categorizing construct [20], [21]. It is an approach similar to that of [8], who however limit their analysis of 'Web 2.0 services' to User-Generated Content sites, blogs, social news aggregators and social network sites. The underline premise of this taxonomy model is that technology, in the form of functionalities, features and system design, support and influences the formation of social networks and, consequently, the way interactions occur in these applications, and vice-and-versa [77], [85], [99]. While the centre of the interaction is always the user, in Social Applications interactions can be focused on digital content (user-content interaction), other users (user-user interaction) or content and other users simultaneously (user-user-content).

In the proposed model, Social Applications are classified into five types of Mobile-Internet 2.0 applications: Dynamic Content Applications, focusing on user interactions with dynamically constructed or enriched digital content (such as Content Sharing services); Social Content Applications, focusing on the interaction between users mediated by digital content; Social Communication Applications, whose focus is transient social interactions between users; Social Matching Applications, focusing on creating new relationships between users; and Social Network Applications, whose focus is to allow and/or encourage sustained relationships between users.

\subsection{Business Models}

Although still relatively recent, literature about business models is extensive and, sometimes, disconnected [39], [60], [79]. However, there seems to be a consensus among business strategy scholars that an overarching concept that "explains how firms make money" is relevant and useful as unit of analysis, especially in highly innovative and fast changing scenarios [88]. Thus, emerging from different fields of business strategy theory, a large number of business model definitions, components, and taxonomies have been proposed, as aptly summarized by [73]. 
In particular, starting from the influential work by [93], the concept of business models finds important application in e-business, an epitomical example of dynamic business environment since its inception in the late 1990s. In this paper, a conceptual model for addressing business models based in the business model definition proposed by [13] is employed. It is composed by four dimensions, which are directly influenced by business model components and dimensions suggested by [3], [66], [67] and [82]:

1. Value creation dimension, reflecting the internal organizational variables and characteristics that guides the strategic approach to the market. Equivalent to the infrastructure dimension proposed by [66], the value creation dimension encompasses the parameters of internal assets, resources, capabilities, processes, and activities;

2. Value delivery dimension, which refers to how the business is articulated in order to reach its consumers and partners. It includes the parameters of value network positioning, key partnerships, delivery and distribution channels, and customer relationship;

3. Value proposition dimension, meaning the effective offering in the form of products and/or services that create value for the user, target customer selection and segmentation, and customer acquisition strategy; and

4. Value appropriation dimension, relative to how the business captures value and generates profit, including revenue channel, revenue sharing, investment, and cost aspects.

A further distinction is needed regarding the revenue channels traditionally employed by digital business. According to [25], [29], [56], [76] and [100], revenue channels can be organized into a number of models, the most common of which include advertisement (based in either display or traffic-based commission), subscription, and transactions (including virtual currency, single purchases, or commerce-based affiliation models). Evidently, these revenue channels can be combined in mixed models that explore the value appropriation advantages of each channel. Mobility characteristics must be considered when designing the value appropriation strategies. Revenue generation mechanisms are highly dependent on the specificities of each technological delivery channel. For instance, mobile devices already incorporate a ready-to-use payment channel in the form of the Mobile Network Operator bill or SIM card. Other than that, premium text messaging can be used to pay for digital content or services. The recent emergence of Application Stores is another revenue generation channel that can be explored in value appropriation strategies.

\section{Methodology}

Given the novelty and complexity that characterize the research topic and the lack of established theory that coherently and completely explains it, the nature of this research is exploratory. Furthermore, the research is constrained by the lack of a firm conceptual and theoretical base specific to the phenomena at hand upon which to draw insights and hypothesis from.

\subsection{Research Design}

The empirical study follows a mixed-methods research strategy. A first quantitative phase involves a cross-sectional survey of Content Sharing and Social Network services offered in Spanish language, whose aim is to map and identify the main characteristics and revenue sources of these types of services. Next, a qualitative phase composed by multiple case studies [102] is conducted, whose objective is to understand the strategic choices behind the roles of technology channel in the value proposition and delivery dimensions and the role of the revenue channels in the value appropriation dimension. The methodological choice of a mixed-methods research strategy thus allows to complementing the empirical positivist survey of the overall supply with an interpretative investigation on specific illustrative cases. The mixed-methods strategy both provides a general picture of the Content Sharing and Social Network services market and a detailed view on the working mechanisms of specific services which can help gaining insight on the overall market dynamics.

The survey instrument was created ad hoc for this research based on the literature review (particularly, common features and characteristics of Social Applications as described by [1], [12], [14], [16], [19], [34], [45], [52], [61], [70], [83], [84], [97] and analysis of secondary sources. The instrument was pre-tested by five experts in Web and Mobile e-Business from academic and business settings that are familiar with Social Applications. It consists of 72 variables of analysis aggregated into eight groups (General Characterization, Social Application Classification, Mobile Features, Core Features, Communication Features, Content Features, Revenue \& Pricing, and Integration \& User Acquisition). Of the 72 variables, 50 are Boolean, indicating the presence or absence of a given functionality in the service, while 6 are descriptive and objective (for instance, the Social Application brand, the name of the company offering the service and its country of origin) and 16 are descriptive but require subjective interpretation, such as the 
Profile Information Detail Level or the Profile Privacy Customization Level. For these 16 variables, a 3-point Likertlike scale ranging from one (low) to three (high).

The overall conceptual framework for the case studies was the business model interpretative conceptualization defined in section 2.3, composed by four dimensions: value proposition, value appropriation, value network, and value delivery. Interview guidelines were elaborated based on the four dimensions of the conceptual framework plus a performance dimension and addressed the company profile, the description of the social application, the use of mobile technologies, the revenue model, the performance of the Social Application, the role of digital content within the service, strategic considerations and future prospective about the firm and the market as a whole, and issues and challenges related to Social Network and Content Sharing services. The focus of the case studies, however, was on the two main research issues that motivate the research: the role of the technology delivery channels (either Internet and/or Mobile) in a multi-channel value delivery strategy and the value appropriation strategies adopted for these services.

\subsection{Sampling, Data Collection and Analysis}

Data collection for the survey was conducted by a team of four researchers in a three-month period between August and October 2009. The survey followed webometrics for web page content analysis and web usage analysis guidelines [90]-[92], [95]. Social Application services to be included in the survey where identified through multiple search engines and directories, specialized websites and aggregators of Social Applications [92] as well as suggestions by interviewees that participated in the case studies. Only commercial services offered in Spanish language were included in the survey, independent of the country of origin. More specifically, the criterion for inclusion in the quantitative research was the language in which the service was offered, not the country of origin of the service provider. Given the limitations of webometrics sampling techniques based on search engines and web indexes [90], [92], the difficulties associated with sampling a specific category of website [92] and the open-ended nature of Mobile-Internet, it cannot be guaranteed that all Spanish-language Social Application services were effectively included in the sample, nor that the sample is actually representative of all Spanish-language Social Applications. However, it can be argued that since commercially-oriented Social Applications invest substantial efforts towards visibility and marketing, those that do not have been identified during the three-month data collection period should not be overly relevant for the purposes of this research. In fact, the selection procedure tends to produce a sample biased towards the most popular and visible services, which closely reflects the actual experience of Social Application users and the business objectives of the companies offering Social Applications.

Each service included in the survey was analyzed by two researchers, the results being confronted by a third researcher that, in the case of discrepancy, conducted a third and final analysis. Researchers utilized each Social Application for a length of time that varied from two to six weeks. Next, the researchers classified the Social Applications according to the five categories described in section 2.2. This selection was based on the stated objectives of the service and the evaluation of the services' functionalities. In particular, Content Sharing applications are those whose declared purpose is to share content or information (especially multimedia content), have user profiles with low level of detail, no connection listings, and whose prominent features are those related to content commenting and content sharing. On the other hand, Social Network applications are those that aim at recreating and managing existing relationships, have user profiles with medium or high level of detail and visible and extensive connection listings. It is important to highlight that not only the presence of a certain feature is considered when classifying the Social Applications, but also many other criteria that are relevant from a usability point of view, like a feature's visibility, ease of use, and actual usage.

The primary unit of analysis for the qualitative phase was the business model of a single Social Application. For the case studies, theoretical sampling was employed [2], [78], i.e., the selection of cases did not follow a statistical logic. Relevance of the Social Application in terms of perceived impact in the Spanish-speaking market and uniqueness in value proposition and appropriation strategies were the primary criteria for inclusion in the sample, while convenience for conducting the case study was considered as the secondary criterion. The main selection criterion (perceived impact) is also an indicator of the Social Application success, which in turn represents a precondition to investigate Critical Success Factors. Perceived impact of a service was subjectively measured by the researchers during the quantitative research phase as a function of the number of citations on specialized news, the number of users and/or active users and revenues. Primary data was collected in telephone semi-structured interviews with top management and secondary data included business news and internal documents [89]. Internal documents included company reports on number and growth rate of users and functionalities usage, as well as drafts of planned functionalities and integration mechanisms with other Social Applications and memos of meetings with clients and service providers. All internal documents were directly handled by the interviewees during or after the interviews. A total of 11 interviews were conducted, with an average duration of one hour and 40 minutes. Interviews were recorded, transcribed and analyzed with content analysis techniques. A summary of each case study was then elaborated based on the interview transcripts and internal documents (when available). Finally, the case study summaries were verified and, eventually, appended by the original interviewees. 


\section{Results}

In this section, the results from the empirical study are presented and analyzed. First, the results for the quantitative and qualitative phases of the study are presented. Next, it follows the identification and discussion of critical success factors (CSF) for Content Sharing and Social Network services in the Spanish-speaking market.

\subsection{Quantitative Results}

A total of 124 Social Applications were identified. Among these, 17\% employ the Web platform as their only delivery channel, while 18\% are based just on the Mobile platform; the remaining $65 \%$ employing both Mobile and Web technologies to deliver its service. This result is a first confirmatory evidence for the relevance of the Mobile-Internet convergence phenomenon. This has important implications regarding the value proposition, as it becomes evident that most Social Application providers seem to be trying to expand their offer (and, in the process, expand the user base) by adding features that leverage on mobile-specific value proposition attributes. For instance, approximately $40 \%$ of the surveyed Social Application services that can be used on both channels have some kind of locationbased feature, a figure that rises to $65 \%$ when considering only the Social Network and Content Sharing categories.

The importance of Social Network and Content Sharing categories is highlighted when the Social Application classification is considered. Overall, Social Network is the most popular category, with $35 \%$ of all surveyed services, while Content Sharing is the third most popular category (22\% of the services). The high number of Social Networks can be explained by the recent hype of this type of Social Application, which may be argued to be experiencing an experimentation period. Social Communication services, representing the earliest and most traditional category of Social Applications (consequently, with somewhat mature business models), are also very common, with 31 (25\%) of the surveyed services.

Regarding core, communication, and content features, the quantitative analysis shows that features that facilitate the establishment of sustained social relationships are the most common, even on services that do not actively promote such aims. For instance, the level detail of user profile information is medium or high in slightly more than $75 \%$ of all Social Applications, which may indicate the disposition to share personal information - which usually is closely related with the aim of socializing. Moreover, content sharing features are also noticeably present even in services that do not belong to the Content Sharing category: $71 \%$ of the surveyed services offer some kind of content sharing functionality, a figure that rises to $92 \%$ when considering only services belonging to the Social Application category. Again, this is further evidence that the main drivers of value proposition among Social Applications seem to be related to maintaining social relationships and sharing social content.

Finally, the results from the Revenue \& Pricing analysis inform on the value appropriation strategy of Social Applications. A first distinction on revenue sources is the use of advertising. As claimed by [8], [17], [45], [86], advertisement-based revenue models are the most common among Social Applications. This is confirmed from the survey results: services that employ advertisement as at least one of the revenue channels in its value appropriation model are $77 \%$ of the total services analyzed. Figure 1 shows the complete results for all revenue channels studied.

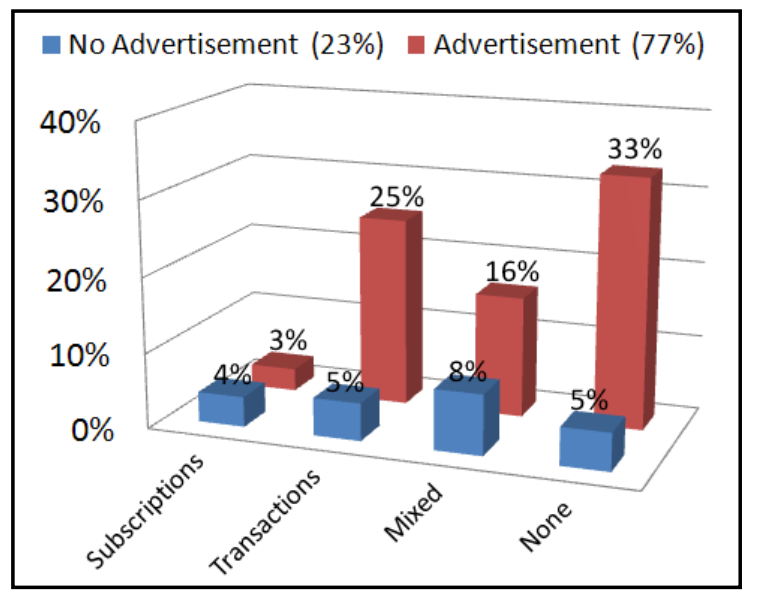

Figure 1: Revenue channels for all surveyed services

Other than the considerations about the preponderance of advertisement, Figure 1 indicates that $38 \%$ of the surveyed services can be used for free (although 33\% are indirectly monetized through advertisement, while only 5\% does not possess any revenue source). Further analysis can be made when the technology delivery channel is 
considered, as seen in Figure 2, which shows the revenue channels for services delivered through the Web channel only, Mobile only, and both Web and Mobile channels.
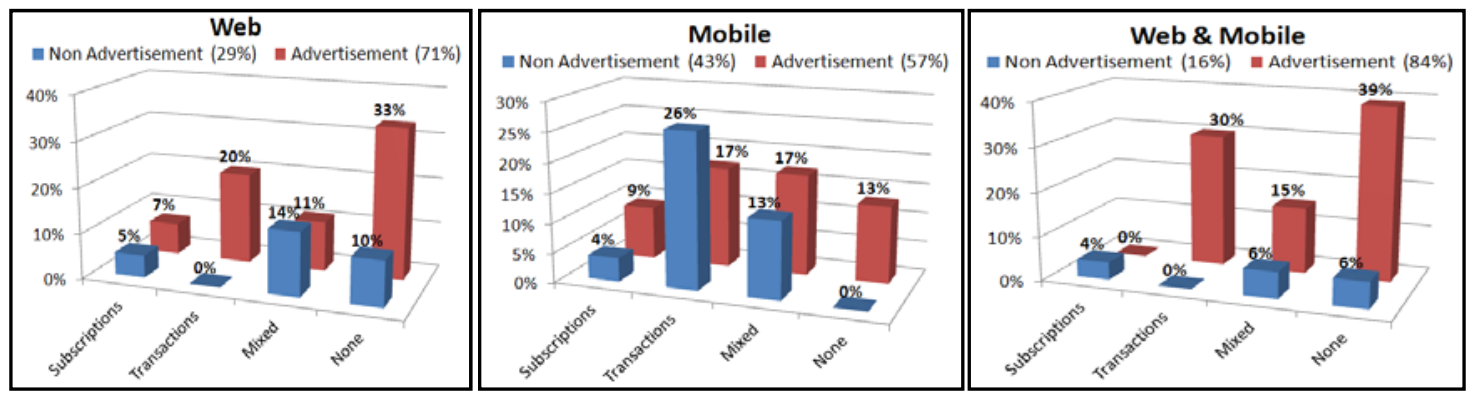

Figure 2: Revenue channels by delivery channel

As seen in Figure 2, the relationship between technology delivery channel and value appropriation strategy is evident. The combined results suggest that the Web channel is more adequate to Advertisement-based strategies, as $71 \%$ of all Web-based services employ Advertisement at least in part and 33\% use Advertisement only. This is even more visible when both channels are employed, as $84 \%$ of the Social Applications thus delivered are based on Advertisement, with almost $40 \%$ relying on Advertisement alone. Conversely, the Mobile channel adds important option to monetize the Social Application services: more than one fourth of the services delivered through the Mobile channel are monetized with transactions.

\subsection{Qualitative Results}

Seven case studies were conducted in this research. Six of the services studied are offered in both Web and Mobile channels, so that the effects of a dual-channel delivery strategy can be investigated, and one service is offered only through the web channel. Of the seven cases studied, two refer to Social Network services, while the remaining five are Content Sharing services. Table 1 shows a summary of the case studies. In Table 1, other than the name of the service and the Social Application category it belongs to, it is also informed the main technological delivery channel (where Mobile+Web indicates a strategic approach where the Mobile is the main channel, complemented by the Web and Web+Mobile indicates the Web as main channel, with additional/complementary functionalities in the Mobile). Moreover, in Table 1 the main functionalities that describe the value proposition of each service are indicated, as well as the main markets it is offered in, its dimension (expressed as number of registered and active users), and a brief overview of its strategic approach in the recent past and the strategic perspectives for the near future.

Table 1: Summary of case studies

\begin{tabular}{|c|c|c|c|c|c|c|}
\hline Service & $\begin{array}{l}\text { Social } \\
\text { Application } \\
\text { Category }\end{array}$ & $\begin{array}{l}\text { Technological } \\
\text { Platform }\end{array}$ & $\begin{array}{l}\text { Value Proposition: } \\
\text { Functionalities }\end{array}$ & $\begin{array}{l}\text { Country } \\
\text { Presence }\end{array}$ & Dimension & Strategy \\
\hline Ipoki & $\begin{array}{l}\text { Content } \\
\text { Share }\end{array}$ & Mobile+Web & $\begin{array}{l}\text { GPS Location, Tracking, } \\
\text { Share Pictures, } \\
\text { Location }\end{array}$ & $\begin{array}{l}\text { Spain, } \\
\text { Philippines, } \\
\text { Argentina, } \\
\text { Venezuela }\end{array}$ & $\begin{array}{l}20,000 \text { registered } \\
\text { users }\end{array}$ & $\begin{array}{l}\text { Enter Chile, Brazil and Mexico, potential technology } \\
\text { provider, word of mouth and social media user } \\
\text { acquisition strategies }\end{array}$ \\
\hline $\begin{array}{l}\text { Estoyen el } \\
\text { Mapa }\end{array}$ & $\begin{array}{l}\text { Content } \\
\text { Share }\end{array}$ & Mobile+Web & $\begin{array}{l}\text { GPS Location, Post } \\
\text { Places in the map, Rate } \\
\text { Places, Comment }\end{array}$ & Mexico & $\begin{array}{l}150,000 \text { visits per } \\
\text { month }\end{array}$ & $\begin{array}{l}\text { Develop and sell GPS technology, offer a free } \\
\text { service, GPS service consolidated, focus on Mexican } \\
\text { market }\end{array}$ \\
\hline Meneame & $\begin{array}{l}\text { Content } \\
\text { Share }\end{array}$ & Web+Mobile & $\begin{array}{l}\text { Content Share, News } \\
\text { and Blog Aggregation, } \\
\text { Chat }\end{array}$ & $\begin{array}{l}\text { Spain, } \\
\text { Mexico, } \\
\text { Argentina }\end{array}$ & $\begin{array}{l}125,000 \text { active users, } \\
2.5 \text { million unique } \\
\text { visitors, } 7 \text { million } \\
\text { visits per month }\end{array}$ & $\begin{array}{l}\text { Open source code, focused on Spanish-speaking } \\
\text { market, Open Source community as a source of } \\
\text { traffic and word of mouth }\end{array}$ \\
\hline Fotolog & $\begin{array}{l}\text { Social } \\
\text { Network }\end{array}$ & Web+Mobile & $\begin{array}{l}\text { Social Network, Blog, } \\
\text { Photo Blog, Micro Blog }\end{array}$ & $\begin{array}{l}\text { USA, Brazil, } \\
\text { Chile, Spain, } \\
\text { Mexico, } \\
\text { Argentina }\end{array}$ & 27 million users & $\begin{array}{l}\text { Acquisition by Hi-Media to leverage the service, } \\
\text { focus on USA Spanish-speaking communities, } \\
\text { agreement with mobile carriers to push into Mobile }\end{array}$ \\
\hline Sonico & $\begin{array}{l}\text { Social } \\
\text { Network }\end{array}$ & Web+Mobile & $\begin{array}{l}\text { Social Network, Games, } \\
\text { Instant Message }\end{array}$ & $\begin{array}{l}\text { Argentina, } \\
\text { Brazil, } \\
\text { Mexico, } \\
\text { Colombia }\end{array}$ & $\begin{array}{l}42 \text { million registered } \\
\text { users, } 27 \text { million } \\
\text { active users }\end{array}$ & $\begin{array}{l}\text { Focus on real users, secure environment, Open } \\
\text { Source code, differentiate Personal and Professional } \\
\text { profiles, Brand recognition, agreement with mobile } \\
\text { carriers to push into Mobile }\end{array}$ \\
\hline Flof & $\begin{array}{l}\text { Content } \\
\text { Share }\end{array}$ & Mobile+Web & $\begin{array}{l}\text { Geo-localization } \\
\text { Platform, Share } \\
\text { Location, Places and } \\
\text { Points of Interest }\end{array}$ & $\begin{array}{l}\text { Argentina, } \\
\text { Uruguay, } \\
\text { Spain, Mexico }\end{array}$ & $\begin{array}{l}10,000 \text { registered } \\
\text { users, } 100,000 \text { visits } \\
\text { per month }\end{array}$ & $\begin{array}{l}\text { Flof as a branding service, focus on software } \\
\text { development, potential technology provider }\end{array}$ \\
\hline $\begin{array}{l}\text { Efecto } \\
\text { Tequila }\end{array}$ & $\begin{array}{l}\text { Content } \\
\text { Share }\end{array}$ & Web & $\begin{array}{l}\text { News and Blog } \\
\text { Aggregation, Chat, } \\
\text { Content Share }\end{array}$ & $\begin{array}{l}\text { Mexico, } \\
\text { Spain, Chile, } \\
\text { Ecuador }\end{array}$ & $\begin{array}{l}1,500 \text { registered } \\
\text { users, } 500,000 \\
\text { pageviews per month }\end{array}$ & $\begin{array}{l}\text { Word of mouth user acquisition strategy, focus in } \\
\text { Mexican market, focus on high quality content }\end{array}$ \\
\hline
\end{tabular}

Five of the Social Applications in the case study analysis were born in the Web environment, taking advantage of the platform's openness as a tool to reach large audiences in the growing Internet market. Fotolog was the first one to be 
launched, in 2002, followed by Meneame in 2005, EstoyEnEIMapa in 2006, Sonico in 2007 and EfectoTequila in 2008. Meneame was born in 2005, aiming at fulfilling a content aggregator and sharing niche focused in Spanish language by that time. The case of Sonico was particular because the enterprise initially offered an electronic postcard service, which eventually led to its entrance in the Social Network market. EstoyEnEIMapa is also a particular case, born in 2006 exclusively in the Web platform as a response of a perceived lack of a Content Sharing site enhanced by localization features in the local market. Soon after the commercial launch, EstoyEnEIMapa adopted the Mobile as their main delivery channel, as it was much simpler and effective to operate the desired location-based functionalities in GPS-enabled devices than on the Web.

The remaining two Social Applications were born in the Mobile environment, following the diffusion of Mobile Internet in their regional markets. Ipoki was first launched in Spain in 2006 and Flof in Argentina in 2008. Ipoki is a Content Share aggregator that offers location services in the mobile context; its main service involves publicly sharing pictures with location metadata. While content production and tagging is done mostly in the mobile device (e.g., by taking pictures with the mobile device's integrated camera), the pictures are accessible mostly from the Web. Flof is a service first made available in the Mobile platform late in 2008 and then emigrated to the Web the year after in order to increase user reach and facilitate access to content. The strategy of Flof is totally different from the others because the enterprise first developed the service in order to show off the software that the enterprise can develop, being thus aimed at brand awareness and portfolio publicity.

In general, the trend observed from the case studies - and, to a good extent, well representative of the Social Application business environment - is that services are created first in the Web platform and then evolve to Mobile. In the case studies, reasons for extending the offering to the Mobile channel involve generally the wish to increase user reach and enrich functionalities with mobile-specific value proposition attributes (such as localization features, facility of instant content generation through mobile device hardware, immediacy of use, access to the mobile device list of contacts, ease of use, and ubiquity). Interestingly, accessing new revenue channels like the easy-to-use payment modes inherent to the mobile (such as the mobile phone bill or premium SMSs) is not considered particularly relevant.

The qualitative phase also allowed gaining deeper insights about the revenue models adopted by Content Sharing and Social Network applications, as summarized in Table 2.

Table 2: Revenue generation mechanisms in case studies

\begin{tabular}{|l|c|c|c|}
\hline \multicolumn{1}{|c|}{$\begin{array}{c}\text { Social } \\
\text { Application }\end{array}$} & Advertisement & Subscriptions & Transactions \\
\hline Ipoki & Google's AdSense & & $\begin{array}{c}\text { Technology } \\
\text { Providers }\end{array}$ \\
\hline EstoyEnEIMapa & $\begin{array}{r}\text { Post Places } \\
\text { LBS \& Technology } \\
\text { Providers }\end{array}$ \\
\hline Meneame & $\begin{array}{r}\text { Display } \\
\text { Advertisement } \\
\text { Fotolog }\end{array}$ & & \\
\hline Sonico & $\begin{array}{r}\text { Advertisement } \\
\text { Display }\end{array}$ & Gold Account & Virtual Currency \\
\hline Flof & $\begin{array}{c}\text { Advertisement } \\
\text { Development }\end{array}$ & Virtual Currency \\
\hline Efecto Tecquila & Coogle's AdSense & & \\
\hline
\end{tabular}

All Social Applications in the case studies employ some mechanism for value appropriation based on Advertisement. Meneame, Fotolog, and Sonico sell advertisement space on a cost-per-view base, and claim that intimate knowledge of their user bases allow advertisers to better target advertisement according to the desired customer segments. On the other hand, Efecto Tecquila replaced the display mechanism with a cost-per-click system, claiming that in this manner it is possible to effectively measure their users' interest in advertisements- which hopefully will increase value for the users and consequently users' willingness to keep using the Social Application. The reasoning that advertisement must be relevant to the user is also followed by Flof and Ipoki, Social Applications that base their revenue models on Google's AdSense, an external advertisement mechanism based on contextual advertisement.

Transaction channels are employed by four out of the seven case studies. Ipoki's main revenue channel is Google's AdSense, but it earns additional revenues through fees paid by technology providers that sell GPS hardware. The case of EstoyEnEIMapa is similar: it is a business unit of Destino GPS, a company that deals on hardware technology embedded with the EstoyEnEIMapa service. Destino GPS pays a fixed fee for each device sold (corresponding to approximately $85 \%$ of its total revenues). The other two cases, Fotolog and Sonico, rely on transactions as secondary revenue channels. In order to pay for value-added content, services, or even virtual gifts, users can acquire virtual currency, and the platform provider earns fees from virtual currency acquisition. An overall message that emerges from Transaction-based revenue channels is that they still tend to represent a secondary 
revenue source. Reasons for this, according to the case studies, are strongly related to the still resilient barriers hampering the adoption of Internet micropayments. Other than being cumbersome to provide credit card data for small transactions, a contingent market barrier is also often cited: the low penetration of credit card coupled with the low confidence in electronic transactions in the Spanish-speaking market, especially in Latin America countries. In light of this, the issue mentioned above regarding the lack of use of the Mobile technology for revenue appropriation becomes even more intriguing.

Sonico and Fotolog are the only Social Applications among the case studies that make use of all revenue mechanisms. The former offers a subscription mechanism to Application Developers willing to offer their applications in Sonico's platform. These developers, in their turn, are allowed to either sell advertisement space in the applications or even to charge for application use through a per-transaction mechanism. However, the percentage of Sonico's revenues derived from Application Developers' subscriptions is still incipient. The latter is experimenting with a Freemium model called Gold Account. In this model, free functionalities are offered to everyone, which are monetized through advertisement and/or fees on virtual currency transactions, as mentioned above. However, improved functionalities such as extended storage space can be accessed through a monthly subscription to a Gold Account.

\subsection{Critical Success Factors}

Finally, the case studies permit to identify a number of critical success factors (CSF) for successful Content Sharing and Social Network services in the Spanish-speaking market. Company success was measured as the perceived impact of the service in the Spanish-speaking market. Indicators of company success employed were the number of citations about the service in specialized news, blogs, and websites, declared number of registered/active users and revenue (when available) and rate of growth of each service in terms of users, active users, and service usage metrics (pageviews, number of shared content items, etc.). The critical success factors were identified by first synthesizing interviewees' spontaneous contributions concerning the causes of their companies' success through content analysis techniques. Moreover, data from secondary sources, case study summaries and interview transcripts were cross-analyzed by the researchers in search of common strategies for growth and revenue generation. Later, these common strategies were compared with success strategies already reported in secondary data. The CSF thus identified were finally validated with four of the original interviewees.

The first CSF identified is the focus on Open Source code and leverage of the Open Source Community. More than substantial savings on acquisitions costs for proprietary software (which represents a particularly relevant benefit for small technological startups in its own), this strategy potentially allows external collaborators to develop and expand the service platforms without hindrances. In this way, quality of service and functionality variety can improve as, for instance, external developers devise new uses for existing functionalities or even design entirely new applications, as in the case of Sonico. For Meneame, this was a particular critical point. The entirety of the platform's code is open to external developers, a decision that brought agile improvements and facilitated the correction of reported system errors. Efecto Tecquila and Ipoki followed the same path. Moreover, an open approach improves the service's visibility in the Open Source community, earning them a constant flow of new users through direct word of mouth.

A related CSF identified from the case studies involves the focus on the integration with other Social Applications. By openly participating in large platforms such as Twitter, Facebook, and YouTube, the studied services were able to freely promote themselves among a large user base and, as result, to acquire new users, especially from niche segments like the Spanish-speaking one. Ipoki is an extremely relevant example of this integration, as it allows its users to automatically update their status on Facebook, Twitter, and Google Maps, among others. This CSF is strongly impacted by the CSF described before, that is, the focus on Open Source code, as interviewees reported that systems and platforms based on Open Source code tend to be more easily integrated with other, similar Open Source-based systems and platforms.

A third CSF is related to leveraging on previous technological know-how and intangible assets. This is exemplified by the Sonico case. Before launching the service as a Social Network, Sonico offered a successful electronic postcard service in Argentina. When the main value proposition shifted towards the Social Network, Sonico was able to obtain 7.3 million registered users in six months thanks to promoting the new service on the database of previous clients. A related case is that of Fotolog, who leveraged on the previous technological know-how of its founders and early employees to avoid a pitfall relatively common among rapid-growth 2.0 services, like Friendster. In these situations, due to lack of technical experience (and, sometimes, financial backing), companies are not able to escalate their technological infra-structures rapidly and effectively enough to keep up with usage growth, resulting in platform breakdowns and low quality service. Early in its history, Fotolog quickly identified the growth trend and correctly improved their IT infrastructure and source codes to cope with the increased volumes of access and traffic, thus avoiding unwanted service breakdowns that tend to fend off users. This was particularly important in establishing a positive reputation as a dependable and reliable service.

A fourth CSF can be identified as the use of multimodal value appropriation strategies. By exploring multiple revenue channels, Social Application companies are able to focus on the different revenue drivers characteristic of both the service objective and technological delivery channel. Revenue drivers characteristic of Content Sharing services include the high volume of accesses, which can be explored through Advertisement-related strategies, and premium 
quality content, which can be monetized through both Subscriptions and Transactions (the precise mechanism depending on the specificities of the digital content). Transaction-based schemes, in particular, are poised to grow in importance in the short term as higher quality content and applications are added to the services, although contextual barriers specific to the Latin America Spanish-speaking market are still extremely relevant. Regarding Advertisement-based revenue generation, the case studies highlighted the importance of investing in non-traditional Advertisement mechanisms, that is, social marketing initiatives. Revenue drivers characteristic of Social Network services are similar, in the sense that they also tend to generate a vast amount of traffic that is appropriate to Advertisement revenues, but social relationships open up vast possibilities in terms of Transactions of virtual goods and use of premium applications and functionalities. The same remark on preferring social marketing strategies instead of traditional display advertisement applies to the Social Network services as well, according to the case studies. The hardships that Social Network services experience when trying to monetize their audiences using traditional advertisement mechanisms, like display and search advertisement, were already pointed out in the academic literature [8], [17], [86], [100] and widely discussed by market analysts and investors specialized in Social Applications. The main benefit deriving from adopting social-oriented marketing mechanisms in Social Applications tends to be a higher acceptance of advertisement among users. Moreover, advertisement that is relevant to the user profile and/or context tends to generate more interest.

Another CSF identified is related to being the first comer into a specific market or niche market. Almost all of the companies analyzed through the cases enjoyed the benefit of being early entrants in their respective geographical markets or in market niches, and reported this as perhaps the most important element determining their business proposition. Evidently, it is not always possible to replicate an early entrant position, but the message is valid when one considers the possibility of focusing the value proposition in order to capitalize on niche markets. This is well exemplified by Sonico, who was able to explore the Spanish-speaking communities in the US that, in the words of one interviewee, "was eager to adopt a Social Network platform that reflected their own identity". Another well known example of this strategy is that of Facebook, which began as an exclusive social network for Harvard students and, later, expanded on to other higher education institutions in order to reach the critical mass needed to open the service for all users.

Finally, a sixth CSF reflects the benefits resulting from establishing partnerships with players from outside the traditional Web value network. Through these partnerships, companies entering the Social Application market are able to leverage on critical external resources and knowledge such as market knowledge, technical knowledge to operate convergent technological platforms, access to customers, customer knowledge, and revenue generation streams. This is especially relevant when considering the convergence between Web and Mobile technologies. Both EstoyEnEIMapa and Ipoki extensively explore this CSF. They base their value appropriation strategies on revenues derived from fees paid by third parties that license their platforms. While this strategic approach may have a negative side, if the partnership becomes a dependency on a single player, if applied correctly it can amplify the reach and options of a Social Application value proposition. The example is once again Sonico, who established a preferential agreement with Mobile Network Operator Claro, one of the largest is South America, in order to extend their value delivery to the Mobile channel using the brand awareness and market penetration of Claro.

Table 3 summarizes the identified Critical Success Factors and the benefits accrued from them as observed in the case studies.

Table 3: Critical success factors and observed benefits

\begin{tabular}{|l|l|}
\hline \multicolumn{1}{|c|}{ Critical Success Factor } & \multicolumn{1}{c}{ Observed Benefits } \\
\hline $\begin{array}{l}\text { Focusing on Open Source } \\
\text { code }\end{array}$ & $\begin{array}{l}\text { Savings on proprietary technology and software } \\
\text { acquisition, simplified integration with other services, } \\
\text { low barriers for external developers, improved } \\
\text { visibility }\end{array}$ \\
\hline $\begin{array}{l}\text { Focusing on the integration } \\
\text { with other Social } \\
\text { Applications }\end{array}$ & $\begin{array}{l}\text { Expanded channels for new user acquisition, } \\
\text { increased service usage }\end{array}$ \\
\hline $\begin{array}{l}\text { Leveraging on previous } \\
\text { technological know-how and } \\
\text { intangible assets }\end{array}$ & $\begin{array}{l}\text { New user acquisition, establishment of key business } \\
\text { partnerships, technical stability and scalability, } \\
\text { infrastructure optimization, positive reputation }\end{array}$ \\
\hline $\begin{array}{l}\text { Using of multimodal value } \\
\text { appropriation strategies }\end{array}$ & $\begin{array}{l}\text { Expanded revenue generation channels, increased } \\
\text { financial stability, higher user acceptance of } \\
\text { advertisement-based models }\end{array}$ \\
\hline Being the first comer & $\begin{array}{l}\text { Establishment of dominant market-share position, } \\
\text { increased customer loyalty, network effects, word of } \\
\text { mouth driving new user acquisition }\end{array}$ \\
\hline $\begin{array}{l}\text { Establishing partnerships } \\
\text { with players from outside the } \\
\text { traditional value chain }\end{array}$ & $\begin{array}{l}\text { Leverage on critical external resources and } \\
\text { knowledge, expanded revenue generation } \\
\text { mechanisms, expanded user base }\end{array}$ \\
\hline
\end{tabular}




\section{Conclusions}

In the context of convergent Mobile and Internet technologies, in particular as the phenomena of Web 2.0 and social technologies consolidate and attract media, academic and business interest, this paper aimed to investigate the relationship between Web 2.0 Social Applications and mobile technologies. In particular, it was sought to explore two particular aspects of Social Applications business models: the role of technology delivery channels in the value delivery and proposition dimensions and the mechanisms for revenue generation in the context of Mobile-Internet convergence. For this purpose, an exploratory and descriptive empirical multi-methods research was conducted. Based on a previous conceptual framework [20], [21], this research approach allowed to investigate both the Social Application offering and the strategic reasoning behind the business model design choices. In particular, the study was limited to the Spanish-speaking market and focused on Social Network and Content Sharing services.

In the light of methodological limitations related to sampling and case study research strategy, it is important to note that the specific results in this study cannot be generalized, and even the identified critical success factors should be further analyzed in other settings before claiming universality. First of all, it should be noted that there may be a number of biases in data analysis related to the subjective aspects of the qualitative research methods employed. Second, context-specific economic, social, institutional, and cultural issues factors related to the Spanish-Speaking market can be proven to impact successful Social Application strategies. In this investigation, no such contextspecific issues were reported, as it was not part of the research objectives, but this can be a focal point for future works in this topic.

However, the present research allows important insights regarding the role of technological channel in the value proposition, value delivery, and value appropriation dimensions of Social Application business models, especially in the light of the case study results. First of all, it was shown the unquestionable link between technological delivery channel and preferable revenue channel, given the particular revenue drivers of each channel. In particular, both quantitative and qualitative empirical evidence corroborate the prevalent view that the Web channel is more appropriate to Advertisement-based revenue models, while the Mobile technology opens up new and relevant opportunities for value appropriation. When also the specific functionalities and value-added features that mobile technologies allow are considered, it results that the expansion of Social Application services to the Mobile domain represents a relevant implication for managers and investors. Social Application providers, however, should observe the current trend towards more refined Advertisement mechanisms, that is, social-oriented marketing strategies instead of traditional display and search advertisement. Different results of the empirical study confirm that the convergence of the Mobile and Internet technology domains is already an affirmed reality, and that is expected to grow even more in importance in the near and medium future.

Finally, the main theoretical contribution of this exploratory research lies in the identification of six critical success factors for Content Sharing and Social Network services, whose validity can be further tested and verified in future works. Moreover, the conceptual framework used in this research can help guide future investigations on the evolution of other Social Application markets and, eventually, the identification of context-dependent strategic issues and success factors.

\section{Acknowledgments}

The authors would like to acknowledge the financial support by the Brazilian government agencies CAPES (Comissão de Aperfeiçoamento de Pessoal de Nível Superior) and CNPq (Conselho Nacional de Pesquisa).

\section{References}

[1] P. Anderson, What is Web 2.0? Ideas, technologies and implications for education, JISC Technology and Standards Watch, Bristol, Technical Report, 2007.

[2] C. F. Auerbach and L. B. Silverstein, Qualitative Data - An Introduction to Coding and Analysis. New York: New York University Press, 2003, pp. 202.

[3] P. Ballon, Business modelling revisited: the configuration of control and value, info, vol. 9, no. 5, pp. 6-19, 2007.

[4] S. J. Barnes, The mobile commerce value chain: analysis and future developments, International Journal of Information Management, vol. 22, no. 2, pp. 91-108, 2002.

[5] S. J. Barnes, Enterprise mobility: concepts and examples, International Journal of Mobile Communications, vol. 1, no. 14, pp. 341-359, 2003.

[6] BBC. (2005, July) News Corp in $\$ 580 m$ internet buy. BBC News - Business. [Online]. Available: http://news.bbc.co.uk/2/hi/business/4695495.stm.

[7] D. Beer, Social network sites... revisiting the story so far: A response to danah boyd \& Nicole Ellison, Journal of Computer-Mediated Communications, vol. 13, no. 2, pp. 516-529, 2008.

[8] J-S. Beuscart and K. Mellet, Business Models of the Web 2.0: Advertising or the Tale of Two Stories, Communications \& Strategies, Special Issue, November, pp. 165-181, 2008. 
[9] G. Bloch-Morhange and E. Fontela, Mobile communication from voice to data - A morphological analysis, Info, vol. 5, no. 2, pp. 24-33, 2003.

[10] L. Bourdeau, J-C. Chebat, and C. Couturier, Internet consumer value of university students: E-mail-vs.-Web users, Journal of Retailing and Consumer Services, vol. 9, no. 2, pp. 61-69, 2002.

[11] H. Bouwman, C. Carlsson, P. Walden, and F. Molina-Castillo, Trends in mobile services in Finland 2004-2006: from ringtones to mobile internet, Info, vol. 10, no. 2, pp. 75-93, 2008.

[12] K. Chai, V. Potdar, and E. Chang, A Survey of Revenue Models for Current Generation Social Software's Systems, in Computational Science and Its Applications, Heidelber: Springer Berlin, 2007, pp. 724-738.

[13] H. Chesbrough and R. S. Rosenbloom, The role of the business model in capturing value from innovation: evidence from Xerox Corporation's technology spin-off companies, Industrial and Corporate Change, vol. 22, no. 3, pp. 529-555, 2002.

[14] I-P. Chiang, C-Y. Huang, and C-W. Huang, Characterizing Web Users' Degree of Web 2.0-ness, Journal of the American Society for Information Science and Technology, vol. 60, no. 7, pp. 1349-1357, 2009.

[15] I. Clarke, Emerging value propositions for m-commerce, Journal of Business Strategies, vol. 18, no. 2, pp. 133148, 2001.

[16] R. Clarke, Web 2.0 as Syndication, Journal of Theoretical and Applied Electronic Commerce Research, vol. 3, no. 2, pp. 30-43, 2008.

[17] E. K. Clemons, The complex problem of monetizing virtual electronic social networks, Decision Support Systems, vol. 48, no. 1, pp. 46-56, 2009.

[18] comScore. (2009, September) Google Sites Surpasses 10 Billion Video Views in August. [Online]. Available: http://comscore.com/Press Events/Press Releases/2009/9/Google Sites Surpasses 10 Billion Video Views in August.

[19] E. Constantinides and S. J. Fountain, Web 2.0: Conceptual foundations and marketing issues, Journal of Direct, Data and Digital Marketing Practice, vol. 9, no. 3, pp. 231-244, 2008.

[20] M. N. Cortimiglia, Mobile-Internet 2.0 Business Models: A Reference Framework, Ph.D. on Management Engineering, Politecnico di Milano, Milan, 2010.

[21] M. N. Cortimiglia, F. Renga, and A. Rangone, A Taxonomy Schema for Web 2.0 and Mobile 2.0 Applications, in Proceedings of the International Conference on e-Business, Milan, Italy, 2009, pp. 69-76.

[22] R. R. Dholakia and N. Dholakia, Mobility and markets: emerging outlines of $\mathrm{m}$-commerce, Journal of Business Research, vol. 57, no. 12, pp. 1391-1396, 2004.

[23] T. Dunnewijk and S. Hultèn, A brief history of mobile communication in Europe, Telematics and Informatics, vol. 24, no. 3, pp. 164-179, 2007.

[24] H. Eijkman, Web 2.0 as a non-foundational network-centric learning space, Campus-Wide Information Systems, vol. 25, no. 2, pp. 93-104, 2008.

[25] A. Enders, H. Hungenberg, H. Denker, and S. Mauch, The long tail of social networking. Revenue models of social networking sites, European Management Journal, vol. 26, no. 3, pp. 199-211, 2008.

[26] Caterina Fake. (2005, March) Yahoo actually does acquire Flickr. [Online]. Available: http://blog.flickr.net/en/2005/03/20/yahoo-actually-does-acquire-flickr/.

[27] J. L. Funk, The future of mobile phone-based Intranet applications: A view from Japan, Technovation, vol. 26, no. 12, pp. 1337-1346, 2006.

[28] J. L. Funk, The emerging value network in the mobile phone industry: The case of Japan and its implications for the rest of the world, Telecommunications Policy, vol. 33, no. 1-2, pp. 4-18, 2009.

[29] J. M. Gallaugher, P. Auger, and A. Barnir, Revenue streams and digital content providers: an empirical investigation, Information \& Management, vol. 38, no. 7, pp. 473-485, 2001.

[30] D. Ganley and C. Lampe, The ties that bind: Social network principles in online communities, Decision Support Systems, vol. 47, no. 3, pp. 266-274, 2009.

[31] Google. (2006, October) Google to Acquire YouTube for $\$ 1.65$ Billion in Stock. [Online]. Available: http://www.google.com/press/pressrel/google youtube.html

[32] W. G. Griswold, Five Enablers for Mobile 2.0. Computer, vol. 40, no. 10, pp. 96-98, 2007.

[33] L. Grossman. (2006, December) Time's Person of the Year: You. Time Magazine. [Online]. Available: http://www.time.com/time/magazine/article/0,9171,1569514,00.html.

[34] G. Hearn, M. Foth, and H. Gray, Applications and implementations of new media in corporate communications: An action research approach, Corporate Communications: An International Journal, vol. 14, no. 1, pp. 49-61, 2009.

[35] J. Hendler and J. Golbeck, Metcalfe's law, Web 2.0, and the Semantic Web, Web Semantics: Science, Services and Agents on the World Wide Web, vol. 6, no. 1, pp. 14-20, 2008.

[36] L. E. Holmquist, Mobile 2.0, Interactions, vol. 14, no. 2, pp. 46-47, 2007

[37] Information Society and Media Directorate-General of the European Commission, User-Centric Media - Future and Challenges in European Research, Luxemburg: Office for Official Publications of the European Commission, pp. 76, 2007.

[38] W. H. Ip, B. Chen, H. C. W. Lau, and B. Liang, A functional framework for integrating eCRM with workflow management based on customer value, Tsinghua Science \& Technology, vol. 11, no. 1, pp. 65-73, 2006.

[39] M. Janssen, G. Kuk, and R. W. Wagenaar, A survey of Web-based business models for e-government in the Netherlands, Government Information Quarterly, vol. 25, no. 2, pp. 202-220, 2008.

[40] A. Jaokar and T. Fish, Mobile Web 2.0 - The innovator's guide to developing and marketing next generation wireless/mobile applications, London: Futuretext, 2006, pp. 335. 
[41] J. Jeon and S. Lee, Technical trends of mobile web 2.0: What next?, in Proceedings of the $17^{\text {th }}$ International World Web Conference - WWW2008, Beijing, China, 2008.

[42] S. Johnson and D. Holmes. (2011, January) Mobile broadband users seen hitting 1 billion in 2011, Reuters. [Online]. Available: http://www.reuters.com/article/idUSTRE70A2JS20110111.

[43] J. Kallio, M. Tinnilä, and A. Tseng, An international comparison of operator-driven business models, Business Process Management Journal, vol. 12, no. 3, pp. 281-298, 2006.

[44] P. K. Kannan, A. Chang, and A. B. Whinston, E-business and the intermediary role of virtual communities, in ECommerce and V-Business - Digital Enterprise in the Twenty-First Century. Oxford: Butterworth-Heinemman, 2007, pp. 380.

[45] D. J. Kim, K-B. Yue, S. P. Hall, and T. Gates, Global diffusion of the internet XV: Web 2.0 technologies, principles, and applications: A conceptual framework from technology push and demand pull perspective, Communications of the Association for Information Systems, vol. 24, no. 38, pp. 657-672, 2009.

[46] H-W. Kim, H. C. Chan, and S. Gupta, Value-based Adoption of Mobile-Internet: An Empirical Investigation, Decision Support Systems, vol. 43, no. 1, pp. 222-238, 2007.

[47] J. Koh and Y-G. Kim, Knowledge sharing in virtual communities: an e-business perspective, Expert Systems with Applications, vol. 26, no. 2, pp. 155-166, 2004.

[48] S. Kumar and C. Zahn, Mobile communications: evolution and impact on business operations, Technovation, vol. 23, no. 6, pp. 515-520, 2003.

[49] Y. Kuo and C. Yu, 3G Telecommunication operators' challenges and roles: a perspective of mobile commerce value chain, Technovation, vol. 26, no. 2, pp. 1347-1356, 2006

[50] A. Lenhart. (2009, January) Adults and Social Network Websites. Pew Internet \& American Life Project. [Online]. Available: http://www.pewinternet.org/ /media/Files/Reports/2009/PIP Adult social networking data memo FINAL.pdf.pdf.

[51] N. M. Levenburg, Delivering customer value online: an analysis of practices, applications, and performance, Journal of Retailing and Consumer Services, vol. 12, no. 5, pp. 319-331, 2005.

[52] M. Levy, WEB 2.0 implications on knowledge management, Journal of Knowledge Management, vol. 13, no. 1, pp. 120-134, 2009

[53] F. Li and J. Whalley, Deconstruction of the telecommunications industry: from value chains to value networks, Telecommunications Policy, vol. 26, no. 9-10, pp. 451-472, 2002.

[54] Y. Lu, Y. Dong, and B. Wang, The Mobile Business Value Chain in China: a case study, International Journal of Electronic Business, vol. 5, no. 5, pp. 460-477, 2007.

[55] G. Lugano, Mobile Social Networking in Theory and Practice, First Monday, vol. 13, no. 11, 2008.

[56] G. T. Lumpkin and G. G. Dess, E-business strategies and internet business models: How the internet adds value, Organizational Dynamics, vol. 33, no. 2, pp. 161-173, 2004.

[57] M. Marr and P. Sanders. (2007, August) Disney Buys Kid's Social-Network Site. The Wall Street Journal. [Online]. Available: http://online.wsj.com/article/SB118599768804085026.html.

[58] P. R. Messinger, E. Stroulia, K. Lyons, M. Bone, R. H. Niu, K. Smirnov, and S. Perelgut, Virtual worlds - past, present, and future: New directions in social computing, Decision Support Systems, vol. 47, no. 3, pp. 204-228, 2009.

[59] M. Stanley. (2009, December) The Mobile Internet Report. Morgan Stanley Research. [Online]. Available: http://www.morganstanley.com/institutional/techresearch/pdfs/mobile internet report.pdf.

[60] M. Morris, M. Schindehutte, and J. Allen, The entrepreneur's business model: towards a unified perspective, Journal of Business Research, vol. 58, no. 6, pp. 726-735, 2005.

[61] S. Murugesan, Understanding Web 2.0, IT Professional, vol. 9, no. 4, pp. 34-41, 2007.

[62] Nielsen. (2009, November) Time Spent Viewing Video on Social Networking Sites Up 98\% Year-Over-Year In October. [Online]. Available: http://blog.nielsen.com/nielsenwire/online mobile/time-spent-viewing-video-on-socialnetworking-sites-up-98-year-over-year-in-october/.

[63] T. O'Reilly. (2005, September) What is Web 2.0? Design patterns and business models for the next generation of software. [Online]. Available: http://oreilly.com/web2/archive/what-is-web-20.html.

[64] D. D. Oberhelman, Coming to terms with Web 2.0, Reference Reviews, vol. 21, no. 7, pp. 5-6, 2007.

[65] S. Okazaki, Mobile advertising adoption by multinationals - Senior executives' initial responses, Internet Research, vol. 15, no. 2, pp. 160-180, 2005.

[66] A. Osterwalder and Y. Pigneur, An e-business model ontology for modelling e-business, in Proceedings of the 15th Bled eConference, Bled, Slovenia, June 17-19, 2002.

[67] A. Osterwalder, The Business Model Ontology: A proposition in a design science approach, Doctoral Thesis on Management Informatics, Universite de Lausanne, Lausanne, 2004.

[68] J. W. Overby and E-J. Lee, The effects of utilitarian and hedonic online shopping value on consumer preference and intentions, Journal of Business Research, vol. 59, no. 10-11, pp. 1160-1166, 2006.

[69] N. Pagiavlas, P. Marburger, M. Stratmann, and S. Young, Mobile Business - Comprehensive Marketing Strategies or Merely IT Expenses? A Case Study of the US Airline Industry, Journal of Electronic Commerce Research, vol. 6, no. 3, pp. 251-261, 2005.

[70] M. Parameswaran and A. B. Whinston, Social computing: An overview, The Communications of the Association for Information Systems, vol. 19, no. 1, pp. 762-780, 2006.

[71] L. Parker, Second Life: the seventh face of the library?, Program: electronic library and information systems, vol. 42, no. 3, pp. 232-242, 2008.

[72] C. Pascu, D. Osimo, M. Ulbrich, G. Turlea, and J. C. Burgelman, The potential disruptive impact of Internet 2 based technologies, First Monday, vol. 12, no. 3, 2007. 
[73] A. G. Pateli and G. M. Giaglis, A research framework for analysing eBusiness models, European Journal of Information Systems, vol. 13, no. 4, pp. 302-314, 2004

[74] J. Peppard and A. Rylander, Products and services in cyberspace, International Journal of Information Management, vol. 25, no. 4, pp. 335-345, 2005.

[75] C. Perey, Mobile Social Networking: Communities and Content on the Move. UK: Informa UK, 2008, pp. 266.

[76] R. Rajala, M. Rossi, V. K. Tuunainen, and J. Vihinen, Revenue logics of mobile entertainment software Observations from companies producing mobile games, Journal of Theoretical and Applied Electronic Commerce, vol. 2, no. 2, pp. 34-47, 2007.

[77] R. Recuero, Redes Sociais na Internet. Porto Alegre, Brazil: Sulina, 2009, pp. 191.

[78] J. Ritchie and J. Lewis, Qualitative Research Practice - A Guide for Social Sciences Students and Researchers. London: SAGE Publications, pp. 336, 2003.

[79] R. Samavi, E. Yu, and T. Topaloglou, Strategic reasoning about business models: a conceptual modeling approach, Information Systems and e-Business Management, vol. 7, no. 2, pp. 171-198, 2009.

[80] M-S. Scale, Facebook as a social search engine and the implications for libraries in the twenty-first century, Library Hi Tech, vol. 26, no. 4, pp. 540-556, 2008.

[81] F. K. Schlosser, Can managers use handheld technologies to support salespeople?, Qualitative Market Research: An International Journal, vol. 10, no. 2, pp. 183-198, 2007.

[82] S. M. Shafer, H. J. Smith, and J. C. Linder, The power of business models, Business Horizons, vol. 48, no. 3, pp. 199-207, 2005.

[83] G. Shao, Understanding the appeal of user-generated media: a uses and gratification perspective, Internet Research, vol. 19, no. 1, pp. 7-25, 2009.

[84] A. Shuen, Web 2.0: A Strategy Guide, Sebastopol, CA: O’Reilly Media, 2008, pp. 266.

[85] D. Skog, Social interaction in virtual communities: the significance of technology, International Journal of Web Based Communities, vol. 1, no. 4, pp. 464-474, 2005

[86] T. J. Spaulding, How can virtual communities create value for business?, Electronic Commerce Research and Applications, vol. 9, no. 1, pp. 38-49, 2010.

[87] D. Tapscott and A. D. Williams, Wikinomics - How Mass Collaboration Changes Everything. New York: Penguin, 2006, pp. 320.

[88] D. J. Teece, Business Models, Business Strategy and Innovation, Long Range Planning, vol. 43, no. 2-3, pp. $172-194,2010$

[89] P. Tharenou, R. Donohue, and B. Cooper, Management Research Methods. Cambridge, U.K.: Cambridge University Press, pp. 338, 2007.

[90] M. Thelwall, Bibliometrics to webometrics, Journal of Information Science, vol. 34, no. 4, pp. 605-621, 2008.

[91] M. Thelwall, Introduction to Webometrics: Quantitative Web Research for the Social Sciences. New York: Morgan \& Claypool, 2009.

[92] M. Thelwall, L. Vaughan, and L. Björneborn, Webometrics, Annual Review of Information Science and Technology, vol. 39, pp. 81-135, 2005.

[93] P. Timmers, Business models for electronic markets, Journal on Electronic Markets, vol. 8, no. 2, pp. 3-8, 1998.

[94] R. van den Dam, E. Nelson, and Z. Lozinski (2010, June). The changing face of communication - Social networking's growing influence on telecom providers, [Online]. Available: $\mathrm{ftp}: / /$ public.dhe.ibm.com/common/ssi/ecm/en/gbe03121usen/GBE03121USEN.PDF.

[95] N. Vanti, Os links e os estudos webométricos, Ciência da Informação, vol. 34, no. 1, pp. 78-88, 2005

[96] C. Venezia and V. Allee, Supporting mobile worker networks: components for effective workplaces, Journal of Corporate Real Estate, vol. 9, no. 3, pp. 168-182, 2007.

[97] W. A. Warr, Social software: fun and games, or business tools?, Journal of Information Science, vol. 34, no. 4, pp. 591-604, 2008.

[98] R. Waters and P. Taylor. (2005, September) Ebay, Skype deal challenges rivals. [Online]. Available: http://www.ft.com/cms/s/2/45b40bd0-2326-11da-86cc-00000e2511c8.html.

[99] B. Wellman, J. Salaff, D. Dimitrova, L. Garton, M. Gulia, and C. Haythornthwaite, Computer Networks as Social Networks: Collaborative Work, Telework, and Virtual Community, Annual Review of Sociology, vol. 22, pp. 213238, January, 1996.

[100] S. Wunsch-Vincent and G. Vickery, Participative Web: User-Created Content: Web 2.0, Wikis and Social Networking, Paris: OECD, pp. 124, 2007.

[101]D. C. Wyld, Management 2.0: a primer on blogging for executives, Management Research News, vol. 31, no. 6, pp. 448-483, 2008.

[102] R. K. Yin, Case Study Research: Design and Methods (2nd ed.). Thousand Oaks: Sage Publications, 1994.

[103]Z. Zhang and S. M. Jasimuddin, Toward a Strategic Framework of Mobile Knowledge Management, Knowledge and Process Management, vol. 15, no. 2, pp. 87-96, 2008. 